other children in their families. At the same time, a study was made of polioviruses recovered from flies caught in the area of the trial to see if they were related to those used in vaccination.

The investigation centred on a group of families living in the same village. In each a single child under two years of age, the index child, received the trivalent vaccine on two occasions. In most of the families there were several children under five years of age. The whole group of vaccinees and sibling contacts was tested for enteroviruses and antibodylevels by means of rectal swabs and blood sampling before, during and after the trial.

The results showed that, in general, the immunizing capacity of this particular vaccine, though moderately good, was not entirely satisfactory. Its effectiveness varied considerably for each of the three strains of poliovirus included. The post-vaccinal response to the Typo 3 component was excellent; the first dose produced antibody conversion in 79 per cent of susceptible vaccinees, the second in 91 per cent. For Type 1 the conversion-rate was only 35 per cent after the first dose and 71 per cent after the second dose, while the Type 2 strain had little effect-only 35 per cent being converted even after the second dose. There was some evidence that heavy nonpoliomyelitis enterovirus infection preceding the trial reduced the response to the Type 1 component to some extent, and that such inhibition was possibly due to $E C H O$ virus 12. This interference did not seem to affect Type 3 responses, and the situation with regard to Type 2 was difficult to evaluate. On the whole, interference by enteroviruses was not of great importance; but interference between the vaccine strains themselves was of some significancethe highly infectious Type $\mathbf{3}$ seemed to some extent to crowd out the competing polioviruses, as well as other enteroviruses. It might well be desirable to enhance the future efficiency of this particular tri- valent vaccine by reducing its content of Type poliovirus and increasing the dose of the other types. particularly Type 2.

The degree of spread of attenuated vaccine strains within families, from the index child to other young children, proved to be considerable, the conversion. rates among susceptible siblings for Types 1 and 3 being 85 per cent and 77 per cent respectively. Type 2 had little opportunity to spread as it infected so few vaccinees. The speed of spread was impressive Vaccinees could be shown to be excreting virus within $18 \mathrm{hr}$. of administration, and at least one sibling contact had picked it up within five days of the original infection. This is consistent with the familiar clinical experience that, in family outbreaks caused by wild virulent strains, several cases often appear within a day or two of each other, giving the false impression that a single extra-familial source has been responsible for a number of separate infections.

It was noted that susceptible children, whether vaccinees or only contacts, excreted Type 3 virus after infection for periods of up to 40 days. Half were infectious for at least three weeks. This did not happen with children who had some level of prevaccinal antibodies; most of these failed to become infected at all and those who were infected excreted virus for only 2-4 days on the average.

Although it proved surprisingly easy to recover polioviruses and other enteroviruses from flies trapped in the village during the trial, and although the kinds of virus recovered roughly paralleled in incidence those found in rectal swabs collected from children studies, the evidence provided by genetic markers was that many of the Type 3 insect-borne strains were, in fact, wild ones. But not all could be so identified, and it seems quite possible that flies are capable of picking up and disseminating the attenuated strains used in oral poliovaccine campaigns.

\title{
INSECTS OF THE PACIFIC AND ANTARCTIC AREA
}

$\mathrm{T}$ HE first report on the zoogeography and evolution of Pacific insects and studies of airborne insects in the antarctic area, which was supported mainly by grants from the U.S. National Science Foundation, the U.S. Office of Naval Research, U.S. Antarctic Research Program, the J. S. Guggenheim Memorial Foundation, and the U.S. Educational Foundation (Fulbright fellowship), has recently been published *.

Dr. Gressitt is to be complimented on the energy and thoroughness with which he has carried out these projects, and considerable progress has been made in an investigation which will take many years to complete.

In the introduction, Gressitt discusses the history of the zoogeography of the area and the various problems involved. Then follow sections on environment, dispersal, establishment, evolution, nature of island populations and faunal origins and affinities. Next comes a section on the Island Groups including Micronesia. This section is followed by an account

* Problems in the Zoogeography of Pacific and Antarctic Insects. By J. Linsley Gressitt, with appendixes by T. C. Maa, I. M. Mackerras, S. Nakata and $\mathbf{L}$. W. Quate. (Pacifle Insects Monograph, No. 2.) Pp. $127+24$ plates. (Honolulu, Hawaii: Bernice P. Bishop Museum, 1961.) of the Papuan Sub-region, Australia, New Zealand. the Sub-antarctic Islands, and Antarctica. The latter two sections are illustrated by excellent colour photographs and the remainder by good photographic figures. Experiments were made in the sub-antaretic in trapping flying insects by means of many large nets flown from the rigging of a ship. Although insect dispersal by air was demonstrated, most insects arriving on the Antarctic continent by this means would fail to establish themselves, because of lack of appropriate food and environment. However, this would not be the case in many of the Pacific Islands, but the impoverished insect fauna of most islands indicates that this method of dispersal is rarely effective.

The rest of the report, illustrated by excellent distributional maps, consists of sections on the detailed zoogeography in the Pacific area of the insect groups, Cerambycidae and Chrysomelidae, by Dr. Gressitt and, in the appendixes, on the Machaerotidae (Hemiptera Homoptera: Cercopoidea) by Dr. T. C. Maa, Tabanidae (Diptera) by Dr. I. M. Mackerras, Phasmatodae by Dr. Setsuko Nakata, and Psychodidae (Diptera) by L. W. Quate.

W. E. China 